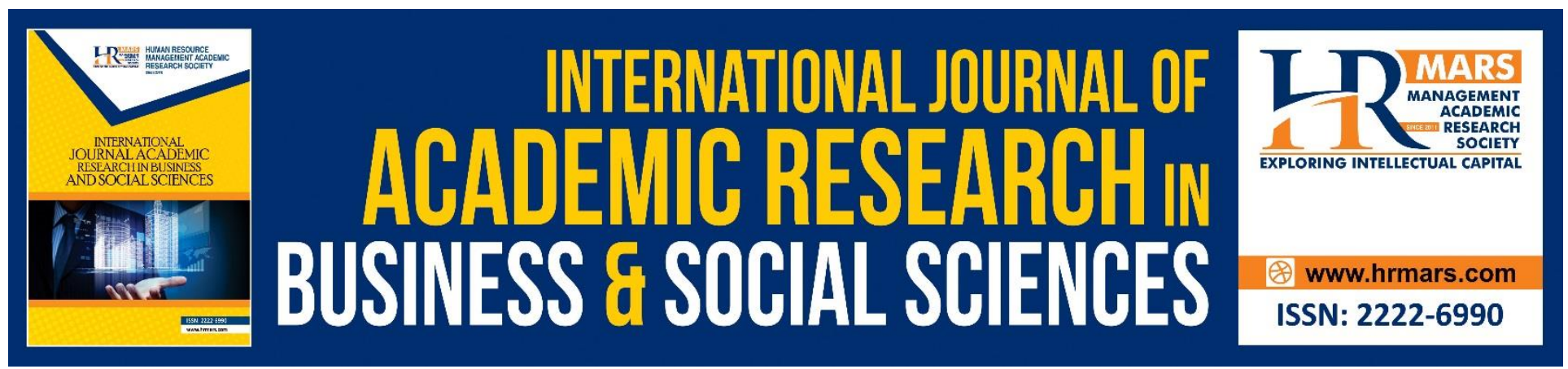

\title{
Reading Strategies Effect on Reading Comprehension Performance of ESL Learners
}

Chiam Kee Swan, Su Luan Wong, Ahmad Fauzi Mohd Ayub, Habsah Hussin

To Link this Article: http://dx.doi.org/10.6007/IJARBSS/v8-i12/5009 DOI: $10.6007 /$ IJARBSS/v8-i12/5009

Received: 11 Oct 2018, Revised: 07 Nov 2018, Accepted: 16 Dec 2018

Published Online: 18 Dec 2018

In-Text Citation: (Swan, Wong, Ayub, \& Hussin, 2018)

To Cite this Article: Swan, C. K., Wong, S. L., Ayub, A. F. M., \& Hussin, H. (2018). Reading Strategies Effect on Reading Comprehension Performance of ESL Learners. International Journal of Academic Research in Business and Social Sciences, 8(12), 231-257.

Copyright: (C) 2018 The Author(s)

Published by Human Resource Management Academic Research Society (www.hrmars.com) This article is published under the Creative Commons Attribution (CC BY 4.0) license. Anyone may reproduce, distribute, translate and create derivative works of this article (for both commercial and non-commercial purposes), subject to full attribution to the original publication and authors. The full terms of this license may be seen at: http://creativecommons.org/licences/by/4.0/legalcode

Vol. 8, No. 12, 2018, Pg. 231 - 257

Full Terms \& Conditions of access and use can be found at http://hrmars.com/index.php/pages/detail/publication-ethics 


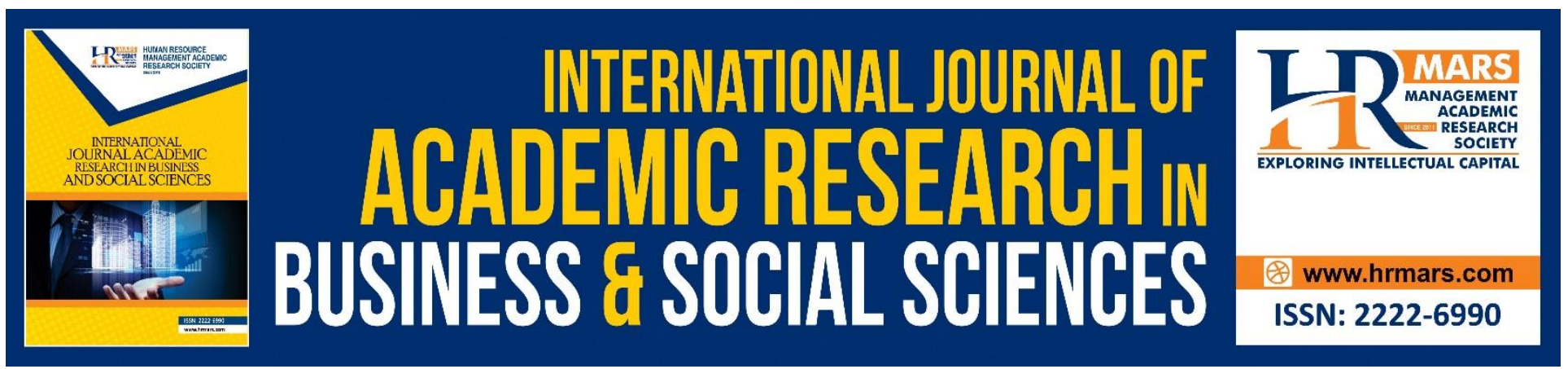

\title{
Reading Strategies Effect on Reading Comprehension Performance of ESL Learners
}

\section{Chiam Kee Swan, Su Luan Wong, Ahmad Fauzi Mohd Ayub, Habsah Hussin}

Faculty of Educational Studies, Universiti Putra Malaysia, 43400 UPM Serdang, Selangor Darul

Ehsan, Malaysia

\begin{abstract}
The purpose of this study was to discover the relative effectiveness of different types of reading strategies on measures of reading comprehension performance for students with different learning styles. Students were separated into four learning style groups (active, sensitive, visual and sequential) based on their scores on the Index of Learning Styles (ILS) questionnaire. The results indicated that students with varying learning styles responded differently to the reading strategies tested in the study. Active learners performed better than other groups when using the keyword and question and answer strategy but performed significantly worse than other groups with the rereading strategy. Sensitive and sequential learners on the other hand performed better than other groups with the rereading strategy. Visual learners did well with the keyword strategy.Of the strategies tested, only the keyword strategy showed consistently positive results for all learning style groups. Each group scored higher on the keyword condition than on the control condition. Hence use of the keyword strategy is highly recommended in classroom environments and incorporating the keywords into texts to make texts easier to understand is a viable method for improving comprehension. The question and answer strategy should be used with caution as it results in sub-par comprehension for learning styles other than the active learning style. Similarly the rereading strategy which works well for sensitive and sequential learners should also be used only for these learners as it confuses active learners. In a nutshell, a student's learning preference will influence the way information is processed and thus selecting and using appropriate reading strategies is essential to ensure the best possible results.
\end{abstract}

Keywords: Reading Strategies, Reading Comprehension Performance, ESL Learners

\section{Introduction}

Reading is indisputably one of the most important aspects of higher or tertiary education through which learner acquire new knowledge, synthesize, evaluate and interpret data to learn more about their subject matter (Noor, 2006). It becomes even more important when one takes into 
INTERNATIONAL JOURNAL OF ACADEMIC RESEARCH IN BUSINESS AND SOCIAL SCIENCES Vol. 8, No. 12, Dec, 2018, E-ISSN: 2222-6990 @ 2018 HRMARS

consideration the fact that as learners' progress through the education system they have to become increasingly independent readers to keep up with the challenges of academic pursuit.

Despite its importance, reading has time and again proven to be a problem area for both learners and educators. According to Ellis (1996), many Malaysian learners at the tertiary level struggle to cope with studies due to poor study skills with the core problem being reading. Some of the contributing causes for this reading problem are factors such as low level of proficiency in the English language, poor knowledge and use of reading strategies, misconceptions about reading and low interest (Majid, Jelas, \& Azman, 2006; Ramaiah, 1997 and Ramaiah \& Nambiar, 1993). However, without expending a great amount of effort, time and resources, one effective and efficient way to handle the current situation would be through reading strategy instruction and this has been supported by Sorrell (1996) and Fehrenbach (1991) who concur that to be a good reader, one must have a large repertoire of reading strategies.

It is imperative to note that different learners respond differently to different reading strategies (Sharma \& Hannafin, 2004). This suggests that learning preferences or learning styles have an effect on the types of reading strategies that a learner may be comfortable with. While a perceptive learner may be aware consciously or subconsciously of the correct reading strategies that best suit his or her learning style, most learners are not which is evidenced by the ongoing problem most learners have with reading independently at the tertiary level. In order to achieve effective reading strategy instruction which result in improved comprehension for all types of learners, the reading strategies taught should best suit the students' learning styles. Additionally, the interaction between learning styles and reading comprehension should also be examined to procure richer and more complex data. Hsieh's (2007) study on the relationships between learning styles and reading strategies points out that the students' learning styles may influence them to process information differently as it passes from sensory memory to short-term memory to long-term memory. This means that while a learning style is more of a preference, since reading is a reflex and the thought process as one reads a sentence is complex and divergent in nature, the choice of reading strategy to use whether implicit or explicit can mean the difference between understanding a sentence and missing the point completely.

Given the fact that resources such as teaching staff and credit hours in most universities are stretched thin, very little can be done to remedy the ongoing problem with reading that most students face. This points towards a need for better understanding of the complex interplay between reading strategies and learning styles; thus justifying a closer examination of the relationship between these two elements. The objective of this experimental study is to examine the relative effectiveness of different types of reading strategies in measuring reading comprehension performance for students with different learning styles during their reading process in an electronic environment. Felder and Soloman's (2003) Index of Learning Style Scale (ILS) will be the measurement employed in this study to identify readers' learning styles. Several reading comprehension tests adapted from the MUET tests using Hsieh's (2007) framework will then be used to gauge Reading comprehension (RC) performance for students with different reading strategies. The reading strategies tested are the 
INTERNATIONAL JOURNAL OF ACADEMIC RESEARCH IN BUSINESS AND SOCIAL SCIENCES

Vol. 8, No. 12, Dec, 2018, E-ISSN: 2222-6990 C 2018 HRMARS

rereading, keyword, and question and answer ( $Q$ \& A) strategy as well as a control testing condition in which no strategy is embedded in the text.

This study has six main research questions

RQ 1: Is there a significant difference between reading comprehension scores of learners using the keyword, rereading, Q\&A strategies and no strategy?

RQ 2: Is there a significant difference between reading comprehension scores of learners having the active, sensitive, visual and sequential learning styles?

RQ 3: Is there a significant difference between reading comprehension scores of active learners using the using the keyword, rereading, Q\&A strategies and no strategy?

RQ 4: Is there a significant difference between reading comprehension scores of sensitive learners using the using the keyword, rereading, Q\&A strategies and no strategy?

RQ 5: Is there a significant difference between reading comprehension scores of visual learners using the using the keyword, rereading, Q\&A strategies and no strategy?

RQ 6: Is there a significant difference between reading comprehension scores of sequential learners using the using the keyword, rereading, Q\&A strategies and no strategy?

\section{Literature Review \\ Rereading}

Rereading is reading over again; an on-going process of repeated encounters with a text where a specific task is set for learners to revisit and rethink about the text in segments. According to Faust and Glenzer (2000) rereading includes rereading a word, a sentence, a passage or even the whole text relying on the different purpose of reading undertaken by individuals ranging from enhancement of comprehension to the enjoyment of literature. In the traditional method of reading, rereading has been always considered the most effective strategy to tackle the enhancement of reading comprehension especially when the text is written in foreign language. The reason; rereading enables learners a chance to re-think the messages implied in the text and further see features they have overlooked in initial reading. Nathan and Stanovich (1991) and later Olmscheid (1999) acknowledge rereading as a useful pedagogical strategy with the ability to increase the learners' reading fluency and a critical connection to reading comprehension. Take for example, a study conducted by Louise (2006), reading fluency was a valuable predictor for learners from the third and fourth grades reading comprehension where single word reading speed was being investigated and rereading was done in their oral language comprehension.

Overall, rereading empowers more language and information acquired as it prompts readers to engage with a text again automatically; using a guided matrix or other task. The purpose of rereading a text is not just to read a text linearly or translating it but to make connections to prior knowledge 
and make sense of what has been gained in the initial reading exercises so that learners are confident at the interpretation of a text. Learners are expected familiarize with the information of the text so that they are able to summarize that information from memory.

It is a belief that the rereading strategy is comparable to reading aloud though they do not share similar scaffolding models. Green (1998), a middle school reading teacher proposed rapid retrieval of information (a rereading instruction) basically to embolden reading aloud. This has initiated motivation which activated higherorder thinking skills (HOTS) which in turn aided to determine the learners' need to revisit words, sentences or paragraphs in the text, thus increasing the learners' competence in completing a particular task. The learners were found contented with this rereading reading strategy. He then added evaluation methods to check balance the process of reading aloud used to improve learners' comprehension skills; skimming and scanning capabilities and their fluency. Another study was on two female from a Japanese college. They were required to think aloud on how they improved comprehension ability with the use of rereading strategies and the findings; rereading strategies increased their comprehension.

In the year 2000, Faust and Glenzer interviewed eighteen fifth-graders on how they do rereading in a text and questioned them about their purpose and objectives while reading. The findings; firstly, rereading strategy aids learners build up an impression of their preferred reading parts/ paragraphs and hence make a deeper connection with the texts. Secondly was the assumption that rereading gives learners' room to comprehend a text differently. Mature learners are able to use their schemata to connect to the content of the reading text.

There are many other relevant researches found in this field. The readership survey which is highly skilled to non-skilled readers involved 154 adults (20 to 84 years old) states that these learners rely on the activation of prior knowledge, rereading of texts, and note taking (Smith, 2000). Two other experiments which dealt with reading on screen are conducted by Faust and Glenzer (2000) and Millis and King (2001) said that there is a significant main effect on learners' memory scores; specifically applicable to those who strategically reread texts. In addition, there is also a significant difference from good to poor readers in reading time as they are able to incorporate new information into their long-term memory during the second readings. In fact, they actually comprehended texts despite dissimilar reading capabilities. However, rereading becomes a bit more tedious when texts are extremely long as rereading is time consuming indeed (Short, Kane \& Peeling, 2000). Thus, it is advisable to use cues like rereading learners' preferred sentences to familiarize the texts.

The researcher finds rereading applicable to this study where recursive reading of text can be implemented with the support of new hypertext and network communication technologies developed well over the last ten to fifteen years ago. The researcher requires the information of such technologies as readers will be able to interact with the text much more closely and as Cornis-Pope and Woodlief (2003) said its associative and dissociative impulses are highlighted and its structures with annotations, linked inter-texts and "winding paths" of circulating signifiers will being enriched. 


\section{Keyword}

The keyword is another reading strategy that is suitable to be tooled online to enhance reading comprehension on screen. Previous studies indicate significant effects; one of which was conducted by McDaniel and Pressley (1989). The experimental study dealt with 75 undergraduates at University of Notre Dame and the results showed that among the three groups i.e. control, keyword, and semantic; the keyword context group appeared to perform significantly better in comprehension and the memory evaluation.

The keyword strategy is a mnemonic (memorization) technique where learners focus and select the central idea of a text and then summarize it as a 'keyword'. It recodes the keyword like a picture mentally and utilizes additional pertinent imagery (relevant data) formed in the mind to the particular keyword. Recalling the keyword is then made possible when it is retrieved from the related data. Avila and Sadoski (1996) and McDaniel and Pressley (1989) acknowledged that it aids to enhance learners' recall abilities. Both pointed out its superior recall and comprehension status which can either be immediate or a week later depending solely on the learners as they are in control while reading the contents of the text. As for Rekrut (1996) the keyword strategy is but a direct vocabulary instruction with a two-steps process. First, the readers will create a list of keywords and then start connecting these keywords meaningfully using their prior knowledge. Sadoski (2005) on one hand takes the role of keyword strategy as vocabulary learning and regarded it a verbal tag for expressing concepts.

In short the many research carried out throughout the past years, have insinuated the effectiveness of keyword strategy in learning new words/ vocabulary and it has also increases learners' comprehension test scores too. Another important point to take note: Normally, impacts are positive when research touch foreign languages or English as Second Language (ESL) based. One particular study was piloted on four Japanese learners who started off with identifying keywords; learning words from word sounds and later proceeded on to meaning (DeCourcy \& Birch, 1993).They did open-ended interviews, went through observations and think-aloud protocols. To grasp the meaning of the text, the learners used keywords strategy and make inferences.

Guillory (1998) tried keyword captions and realized learners were able to identify words from full text easily and they achieved much better results in their comprehension. In addition, Fagan (2003) discovered that keywords strategy is essential to support ESL learners during the reading process. There are all sorts of studies; some experimented on using keywords to halt reading disabilities and others researched on improving comprehension abilities among language minorities. O'Donnell, Weber and McLaughlin (2003) conducted a single case study on a male fifth grader; a Hong Kong citizen by birth went through ten sessions of keywords identifying; a text per session. The sessions begin with a preview of materials and a discussion of the keywords in the text before the initial stage of reading. His best reading scores accomplished reading 186-191 words a minute and read three passages with a total of fifteen questions correctly answered.

The researcher has taken keyword strategy to be one of her implemented reading strategies for this study not only because of all the above findings but due to its knack to function well online Its 
popularity as a must acquire skill to marketing online is amazing. The reason; search engines are crucial to online business and it is essential to rank high in the search engine results. This literary means to be part of the online presence attaining the right keywords is part of the game. With such importance, the researcher believes together with the right learning styles, learners will be able to fly high in their reading comprehension.

\section{Question and Answer (Q\&A)}

The question and answer strategy in point of fact is the Question-Answer Relationship (QAR) developed by Taffy Raphael in 1982 (Mclntosh \& Draper, 1995). This astounding strategy assists learners to ponder on the answers through the questions set from a particular text. More than often learners' assumption is the answer of any questions are directly in the text. They think if they scrutinize each and every part of the given text; they will succeed in finding the correct answers. Therefore, they took up too much time trying extremely hard to find the answers which are not exactly there in text as most questions at the tertiary level require them to inference or even predict outcomes as of today most questions need some amount of critical thinking (HOTS). Frustration mounts and they become agitated. Thus, the four basic Q\&A strategies i.e. Right There, Think and Search, Author and Me, and On My Own should be mastered for them to effectively and efficiently approach the different types of questions.

Raphael (1982) established a concept; learners using Q\&A in their reading comprehension are capable of locating information in the text and their responds to questions are positive. Benito, Foley, Lewis and Prescott (1993) then discovered learners employing Q\&A could figure out the different types of questions and produce satisfactory answers. Q\&A was then found to support reading, answering of questions and learning from texts (McIntosh \& Draper, 1995). Then in 1996, McIntosh and Draper incorporated Q\&A in the teaching of mathematics while Mesmer and Hutchins (2002) used Q\&A in science classes to read charts, tables and figures including answering multiple- choice questions. Finch (2003) did the same with a fifth-grader science class and the effects were encouraging and motivating. Learners took responsibility for their learning; generating their own questions and finding the answers themselves.

In a nutshell, Q\&A is a valuable strategy; once acquired, it does not rust off from the lack of use or be forgotten. Learners will maintain the use of this reading skill (Ezell, Hunsicker, Quinque\& Randolph, 1996). Additionally, educators can apply Q\&A in different contexts and still obtain positive instructional effects (Ezell, Hunsicker \& Ouinque, 1997). Q\&A is also known as an active agent to upsurge learners' metacognitive awareness in the process (Benito et al., 1993). In this study, the third reading strategy chosen by the researcher is this $Q \& A$ which is suitable to be adapted for online use. Q\&A is utilized as a question answer label to highlight text and relate to answers from previously posed questions here. This strategy aids learners to demystify their question-building process to enhance their reading comprehension. 


\section{Methodology \\ Research Design}

In this repeated measures design, each subject receives each of the four treatments followed by the tests. A one month interval between each treatment-test cycle is designated to prevent or discourage carry-over effects from the previous treatment-test cycle. One unique aspect of this research is that the treatment does not quite precede the test. This is because the treatment is essentially the reading strategy embedded within the text which is in turn part of the reading comprehension test. As such, this research does not conform to traditional research procedures where the treatment and testing are entirely separate processes; in the present study, there exists some considerable overlap between procedures.

\section{Participants}

The subjects in this study were 132 Universiti Malaysia Pahang's first and second year students taking compulsory English for Specific Purposes (ESP) classes. The subjects are between the ages of 19 to 22 years and would have had to score at least a Band 3 on the Malaysian University Entrance Test (MUET). The subjects comprise both male and female learners from different racial backgrounds with the vast majority being Malay. Hence the subjects can be comfortably classified as ESL learners.

\section{Questionnaire}

This study uses the Felder Solomon Learning Styles Dimensions (FSLSD) model to identify students' learning styles. It is a 44-item questionnaire for identifying the learning styles according to FSLSD. As mentioned earlier, each learner has a tendency in one direction for each dimension. These tendencies are denoted by odd numbered integers from 1 to 11 . The 44 questions are equally divided between the dimensions with 11 questions for each dimension. The 11 questions are the reason for the range of 1 to 11 for each tendency. When answering a question, for instance, with an active preference, 1 point is added to the value of the active/reflective dimension in the direction of the active pole whereas an answer for a reflective preference adds a value of 1 to the reflective pole. Therefore, each question answered contributes a point to either the first pole of each dimension (active, sensing, visual, or sequential), or to the second pole of each dimension (reflective, intuitive, verbal, or global). The reason why the score in any dimension is always an odd number is because the final score is the difference between the two poles and there are an odd number of questions.

\section{Online Reading Texts}

The texts used for the purpose of this research were MUET reading comprehension passages from the years 2000 to 2002. The texts were selected from years 2000 to 2002 to reduce the chances that the participants have actually done practises using these texts from MUET past year questions since their practises would most probably be from more recent years. A total of 16 texts were selected for the study covering topics such as the environment, health, economy, language, nature, medicine, education, psychology and history. Each test set consists of four texts with an average of 600 words. One set of four texts is maintained as per the original and this serves as the control condition or no strategy testing condition. The remaining texts for the treatment conditions were reproduced three 
INTERNATIONAL JOURNAL OF ACADEMIC RESEARCH IN BUSINESS AND SOCIAL SCIENCES

Vol. 8, No. 12, Dec, 2018, E-ISSN: 2222-6990 C 2018 HRMARS

times in different modes incorporating the three reading strategies - keyword, rereading and question answer relationship.

\section{Keyword Strategy}

Participants undergoing this treatment condition are encouraged to view highlighted keywords related to key learning objectives and test questions. With the highlighted keywords, visual stimuli bring their attention to either activate prior knowledge or to create new connections for meaningful information. Highlights included facts, concepts and procedures in bold and a large font for this treatment. The structure of the page is the same as in the control and rereading treatment groups. However, in this treatment, the students may attend to viewing the highlighted words and then read the rest information related to them. The keyword strategy was also implemented in this study to highlight important factual, conceptual, principal, or procedural information. The selection of keywords were vetted by three experienced MUET examiners and the choice of keywords were determined such as to improve comprehension of the passage content without simply giving away the answers. Hence, the students also view segments of the sentences highlighted with a larger, bold font style. Imagining how to store varied types of information into a functional or hierarchical relationship is necessary here.

\section{Rereading Strategy}

The participants experiencing this treatment condition find a repetition of selected sentences related to specific learning objectives and test questions. This repetition allows them to process information twice. So, an additional 24 pages were designed for this treatment. When participants finish reading the first page and then click on a "Next" button, the selected sentences or paragraphs from the first page appear on the second page word-by-word in teleprompter fashion until a "CONTINUE" button appears. The sentence to be reread will not appear all at once; words will appear sequentially and create the sense of animation. After completing the rereading, the participants then can click on the CONTINUE button to proceed to the rest of the pages. They can also click on a "PREVIOUS" button to go back to the first page.

As the students view the first page, they may be unaware that varied importance levels exist among sentences. However, as they click on the NEXT button, they are forced to read the important sentences again on another page. No NEXT button appears on that page, only PREVIOUS, Direction and CONTINUE buttons. The title and other two topics are also removed. The students' visual attention is on the repeated sentences shown on the screen word by word. They can decide how they can elaborate on the new information in the second visit of the sentences for adding to their prior knowledge base in their long-term memory storage. The topic belonging to the sentences and the page range for that topic are still on the top of the screen. The selection of phrases that appeared in the reread section were again vetted by three experienced MUET examiners. As with the keyword strategy, the choice of text segment was based on text comprehension rather than on the questions following the passage. In fact, the selection of both the keywords and the rereading segments are remarkably similar and the process of selection was done before narrowing down the questions based on Barret's Taxonomy. 
INTERNATIONAL JOURNAL OF ACADEMIC RESEARCH IN BUSINESS AND SOCIAL SCIENCES

Vol. 8, No. 12, Dec, 2018, E-ISSN: 2222-6990 @ 2018 HRMARS

\section{Question and Answer Strategy}

The participants facing this treatment find some sections of the texts are structured in a Q\&A format. The Q\&A format essentially means that large portions of the text are preceded by a question relating to the chunk of text. The revised Web design has a proper length for each page. Students are able to view a chunk (or a segment) of information and then process it in an organized way. This treatment presented four to five Q\&A formats for each passage so that the participants can concentrate on specific learning objectives and related criteria measures. As previously stated, the page layout is the same as in the other three treatments. However, the structure of the text is different. The students' attention is on the question and answer format, which allows them to process information in a chunk.

Throughout the treatment period, the researcher took care to control for diffusion. Diffusion occurs when the nature of the treatment is "leaked" from one treatment/control group to another due to interaction between participants. Once this happens it is possible for the different treatment groups to imitate each other hence causing an equalization of results between groups. It would then become significantly harder to determine which treatment works better under which circumstances. In this study however, the very nature of the treatment somewhat discourages diffusion. This is because the reading strategies are incorporated into the text thus encouraging the subject to use the particular reading strategy at the time of the treatment. For example, it would be very unlikely that a subject in the rereading group did not use that strategy when going through the text since the text is animated in such a way that important phrases appear twice. Similarly in the other groups, the text is configured in such a way as to prompt the reader to use the specific reading strategy. Diffusion hence becomes a non-factor since the tendency is for the subject to follow the strategy incorporated in the text over one that has been leaked out. Also the one month washout period between treatments allows for the "reformatting" of participants to their original states and reading habits.

Aside from internal threats to validity, there are generalizability issues to consider when dealing with the treatment; specifically the interaction of causal relationships over treatment variations. This threat to external validity deals with how the size or direction of a causal relationship varies over different treatment variations (Shadish et al., 2002). What this means is that different variations of how the treatment is implemented may bring about a different effect. For example when randomizing the order of treatment, if a sequence of treatment not present in this study were to be used, the outcome may be different. Similarly an individual treatment may have a different effect from a combination of treatments and the reported effects may derive from the combination and not the individual treatment. To deal with the generalizability issues pertaining to treatment variations we fall back on previous research. According Hsieh (2007), there is a strong assurance that participants undergoing a specific treatment are not using the skills acquired from other treatments any more or less than they usually would under normal circumstances. This is because the nature of the treatment itself which incorporates the reading strategy into the text, thus ensuring that the participants in that treatment group use that particular strategy. Moreover there is the fact that the participants are only exposed to each treatment only once thus making it unlikely that there would be effects from different treatment combinations. Hence the treatment variations are unlikely to play a role in the reading comprehension performance as opposed to the particular treatment itself. 
INTERNATIONAL JOURNAL OF ACADEMIC RESEARCH IN BUSINESS AND SOCIAL SCIENCES

Vol. 8, No. 12, Dec, 2018, E-ISSN: 2222-6990 @ 2018 HRMARS

\section{Reading Comprehension Test}

The participants' reading comprehension performance will be evaluated by a multiple choice question (MCQ) reading comprehension test. This test, adapted from the MUET 2000 to 2002 past year questions comprises 20 items with four answer options: A, B, C or D each. Each correct answer yields one mark and no marks will be awarded or deducted for wrong answers. There are questions requiring participants to draw conclusions, make inferences and evaluate information that is not explicitly stated in the text itself. The unaltered MUET reading comprehension tests consist of 50 questions with 27-30 questions depending on the passages and the remaining questions being of the cloze passage variety. Barrett's Taxonomy of Cognitive Difficulty of Questions (Barrett, 1976) was used to rate each question so that an equal number of questions of the same difficulty are in each of the 4 sets of tests.

\section{Experimental Procedures and Techniques}

The experimental procedure involves four stages (preparation, sampling, implementation and analysis). The preparation stage required the researcher to seek permission from the Centre of Modern Languages and Human Sciences (CMLHS) to (1) take up a half hour of regular lecture time to allow all first and second year students taking English for specific purposes (ESP) courses to complete the ILS questionnaire and (2) to allow the students who qualify for the research to be exempted from the compulsory 10 hours of self-access language learning that they must complete as part of their course assessment if they choose to be part of the research. Students taking the ESP course would usually have to log on the self access language learning software in the computer lab for 10 hours throughout the duration of their course to earn 10 marks for their ESP course. Instead the researcher requested permission from the CMLHS to take four of those hours for qualifying candidates to participate in the study. Instead of using the self access Tell Me More (TMM) software, the participants would spend four hours spread over four months doing reading comprehension tests. Once the permission from the CMLHS has been granted, the researcher would have to discuss with each class lecturer so that a suitable time can be arranged to allow the students to take the ILS questionnaire. The preparation stage is concluded once students from all the ESP classes have completed the ILS questionnaires.

When admitting subjects into a research, it is important for the researcher to control for statistical regression. Statistical regression or regression to the mean becomes a threat to internal validity when subjects are selected to participate in the study due to extremely high or low scores. These "fluke" extreme scores, whether low or high will not be reproduced when the subjects are tested a second time around (they will most likely score closer to the average hence the name regression to the mean); thus leading to the possibility of falsely rejecting a null hypothesis. In this study, subjects were selected to participate in the study based on their learning style scores as measured by the Index of Learning Styles (Felder Solomon, 2003). This measurement is only taken once at the beginning of the study as the learning styles are not expected to change appreciably over the duration of the study. As such, statistical regression ceases to be an internal threat since participant selection into the study is independent of their reading comprehension performance (the dependent variable). 
The second stage, sampling, requires the researcher to tabulate the results obtained from the ILS questionnaires. The candidates who score more than three on only one pole for the active, sensitive, visual and sequential poles are retained as eligible candidates. Those who have no preference for all four dimensions or have preferences for more than one dimension are immediately removed as possible candidates for the study. The shortlisted candidates were then sent memos officially inviting them to be part of the study. The memo outlined all the important details in the study such as the incentives, the duration of the study and the days that participants were required to attend the treatment sessions. The memo also indicated a date by which candidates were to respond to indicate interest to participate. Candidates were not informed of the reasons for separating them into different groups until after the study to control for compensatory rivalry/resentful demoralization. Once the responses were collected, the participants were assigned to groups according to their learning styles. Each group consisted of one learning style preference (active, sensitive, visual and sequential). The groups were formed as described in the participants section. A memo was sent to each participant confirming their admission into the study. Another memo was sent to all candidates who did not make the cut regrettably informing them that the quota for the study has been filled and thanking them for their cooperation thus concluding the sampling stage.

The implementation stage involved administering the testing conditions. The students were informed of the time and venue of the treatment-test. All activities were carried out at night in the computer labs. The reason for this time allocation was to ensure that students did not have other engagements causing them to miss sessions (UMP students stay on campus, therefore it is possible to have sessions at night without causing any great inconvenience to the students). The one month gap between treatments is to allow desensitization of the research subjects to the effects of earlier tests therefore minimizing the threat of testing. A longer gap was not used due to the possibility of internal threats to validity such as maturation, history or maturation-selection interaction which are exacerbated by prolonged durations of study. In a study spanning a period of only four months, it is very unlikely that subjects would experience maturation at significantly different rates such that it affects the dependent variable in a measurable magnitude. The experimenter was however careful to control the internal threat from history by ensuring that the duration selected for the research did not coincide with any university activities such as reading week or language vaganza which were annual events held in UMP or MUET reading comprehension drills which were held at the end of every semester. Any one of these events could possibly affect the participants' reading comprehension performance and foil the experiment by offering an alternative hypothesis to explain differences in the reading comprehension performance of the subjects.

During the treatments, subjects were given the text which has the reading strategy incorporated into it. Subjects were instructed to read the texts carefully and answer the multiple choice questions that followed. The purpose of this research was to answer the question of which reading strategy best suited learners of different learning styles. The development and use of reading strategies by participants on the long term were not effectively assessed in the present study. Instead this research is geared towards the development of more easily comprehensible course material and informing educators on how best to address a classroom comprising learners of varied learning preferences. By 
the end of the fourth month, each group would have received all four treatments and the researcher proceeded to data analysis.

Throughout the duration of the treatment, the researcher had to control for compensatory rivalry and/or resentful demoralization. Compensatory rivalry and resentful demoralization are two conditions that could threaten internal validity if not controlled. The first condition is one in which participants in the control group are aware of the special treatment given to their counterparts and work extra hard just to show that they can compete with the treatment. This competition between groups would make it harder to detect the effects of the treatment. Resentful demoralization on the other hand works in the exact opposite way. In this condition, participants know of the special treatment given to their counterparts and become angry and give up. In this event, the results would suggest that the treatment is much better than it actually is. When using the repeated measures design however, each group undergoes the each of the treatment conditions. This therefore ensures that there is equality between groups in terms of goods received. Furthermore, the groups were not informed of the existence of other treatment groups.

The fourth and final stage of the research is the analysis of data. First the reliability coefficients will be calculated for the reading comprehension tests and the Index of Learning Styles. The mean scores and standard deviations of each of the learning style groups were used to illustrate the participants' overall achievement. The details of how the data analysis was done will be further discussed in the method of data analysis section.

\section{Data Analysis}

The data in this study was for the larger part analyzed quantitatively. Statistical significance was accepted at the .05 level of confidence. In this study, the statistical test used was the two-way split plot analysis of variance (SPANOVA) to answer research questions one, two, three and four.. This method of analysis is used because this study comprises two categorical independent variables and one continuous dependent variable, making the SPANOVA the most logical data analysis tool for data mining. Analysis of Variance (ANOVA) is made all the more relevant given that the primary objective of this study is to compare means of reading comprehension performance. The mixed betweenwithin two-way ANOVA will reveal whether there is a significant main effect between the groups (i.e two or more groups differ significantly) and also whether there is a significant interaction effect (indicating that the influence of one independent variable on the dependent variable depends also on the level of a second independent variable). Since there were significant interaction effects, Tukey's HSD post hoc comparisons were carried out to investigate the interaction between the variables as well as to answer the remaining research questions definitively.

\section{Results}

\section{Split Plot Analysis of Variance}

The split plotanalysis of variance (SPANOVA) is carried out to examine the relationship between learning styles, reading strategies and reading comprehension performance. A Mauchly's Test of Sphericity is conducted to determine whether the univariate statistics can be referred to. The 
INTERNATIONAL JOURNAL OF ACADEMIC RESEARCH IN BUSINESS AND SOCIAL SCIENCES Vol. 8, No. 12, Dec, 2018, E-ISSN: 2222-6990 @ 2018 HRMARS

approximate Chi-square value obtained was 11.126 with a corresponding $p$-value of 0.049 , which is just narrowly below the significance level of 0.05 . Hence the assumption of sphericity for repeated measures ANOVA no longer holds.

Since the assumption of sphericity has been violated, the univariate statistics cannot be referred to. Instead the multivariate statistics which do not make the assumption of sphericity are used. Referring to the Wilks' Lambda test statistic there is a significant interaction effect between the reading strategy and learning style groups, $\mathrm{p}<.05, \mathrm{~F}(9,306.801)=.00$ This means the effects of the reading strategy on reading comprehension performance cannot be measured accurately without taking into account the learning styles of the subjects tested. The partial Eta squared value is .220. Comparing this to the commonly used guideline by Cohen (1988), where $0.01=$ small effect, $0.05=$ moderate effect and $0.14=$ large effect, this result suggests a large effect.

There is also a significant main effect with a large effect size but reporting this given that there is an interaction effect is meaningless as the main effect of reading strategy is moderated by the level of the learning style. As such, a post hoc comparison using Tukey's HSD will be conducted to assess where the difference lies within each group and to attempt to elucidate a clearer understanding of the relationship between the independent variables which have now been identified as having an interaction effect.

\section{Post Hoc Comparisons}

First a series of one way ANOVAs were carried out to discover which testing conditions had learning style groups with significantly different means. Based on the findings, the no strategy condition showed no significant difference between the mean scores for each learning style group, $p>0.05, F(3$, $128)=0.306$. For each of the other testing conditions there was at least one pair of means which differed significantly. The keyword reading strategy had a significant result, $p<0.05, F(3,128)=9.311$; so did the rereading strategy $p<0.05, F(3,128)=25.405$ as well the $Q \& A$ strategy, $p<0.05, F(3,128)=$ 6.951.

Now that it has been established that there are differences between the learning style groups for the keyword, rereading and question and answer strategy, the Tukey's HSD comparison was carried out for each of the testing conditions to ascertain the effect each reading strategy had on reading comprehension for a specific learning style.

Table 1 shows the results of the Tukey's HSD comparisons of the means of reading comprehension scores of the different learning styles for the keyword reading strategy. The results for the keyword reading strategy condition indicate that there are significant differences between the active learning style group $(M=56.03, S D=11.66)$ and the sensitive $(M=45.29, S D=12.06, p=.00)$ and sequential learning style group $(M=44.21, S D=9.60, p=.00)$. There was no significant difference between the means of the active learners $(M=56.03, S D=11.66)$ and the visual learners $(M=52.81, S D=9.75)$ for the keyword reading strategy. Hence the keyword reading strategy benefitted active and visual learners significantly more than it did other learning style groups. 
INTERNATIONAL JOURNAL OF ACADEMIC RESEARCH IN BUSINESS AND SOCIAL SCIENCES

Vol. 8, No. 12, Dec, 2018, E-ISSN: 2222-6990 C 2018 HRMARS

Table 1: Tukey HSD Pairwise Comparison of RC Scores for Different Learning Styles Using the Keyword Reading Strategy

\begin{tabular}{|c|c|c|c|c|c|}
\hline \multirow{2}{*}{$\begin{array}{l}\text { Dependent } \\
\text { Variable }\end{array}$} & (I) Learning & (J) Learning & Mean & Std. Error & Sig \\
\hline & Style & Style & \multicolumn{3}{|l|}{ Difference (I-J) } \\
\hline & & Sensitive & 10.73 & 2.63 & 0.00 \\
\hline & Active & Visual & 3.21 & 2.67 & 0.63 \\
\hline & & Sequential & 11.81 & 2.67 & 0.00 \\
\hline & & Sensitive & -10.73 & 2.63 & 0.00 \\
\hline & Sensitive & Visual & -7.51 & 2.67 & 0.03 \\
\hline \multirow[t]{7}{*}{ Keywords } & & Sequential & 1.07 & 2.67 & 0.98 \\
\hline & & Sensitive & -3.21 & 2.67 & 0.63 \\
\hline & Visual & Visual & 7.51 & 2.67 & 0.03 \\
\hline & & Sequential & 8.59 & 2.71 & 0.01 \\
\hline & & Sensitive & -11.81 & 2.67 & 0.00 \\
\hline & Sequential & Visual & -1.07 & 2.67 & 0.98 \\
\hline & & Sequential & -8.59 & 2.71 & 0.01 \\
\hline
\end{tabular}

The results for the rereading strategy are a little harder to assess. Table 2 shows the results of the Tukey's HSD comparisons of the means of reading comprehension scores of the different learning styles for the rereading strategy. There were significant differences between the active learners $(M=36.47, S D=10.48)$ and sensitive $(M=55.15, S D=11.51, p=.00)$, visual $(M=44.22, S D=14.21, p=.04)$ as well as the sequential learners $(M=58.43, S D=9.54, p=.00)$. In fact for this particular reading strategy, the only two groups that did not differ significantly from each other were the sensitive and sequential groups. Judging from the means, these two groups performed better than the other groups. The significant difference between the active and visual learners means that the active learners performed significantly worse than any other group when using the rereading strategy. 
INTERNATIONAL JOURNAL OF ACADEMIC RESEARCH IN BUSINESS AND SOCIAL SCIENCES

Vol. 8, No. 12, Dec, 2018, E-ISSN: 2222-6990 C 2018 HRMARS

Table 2: Tukey HSD Pairwise Comparison of RC Scores for Different Learning Styles Using the Rereading Strategy

\begin{tabular}{|c|c|c|c|c|c|}
\hline \multirow{2}{*}{$\begin{array}{l}\text { Dependent } \\
\text { Variable }\end{array}$} & (I) Learning & (J) Learning & Mean & Std. Error & \multirow[t]{2}{*}{ Sig } \\
\hline & Style & Style & Difference (I-J) & & \\
\hline \multirow{12}{*}{ Rereading } & & Sensitive & -18.67 & 2.80 & 0.00 \\
\hline & Active & Visual & -7.74 & 2.84 & 0.04 \\
\hline & & Sequential & -21.96 & 2.84 & 0.00 \\
\hline & & Sensitive & 18.67 & 2.80 & 0.00 \\
\hline & Sensitive & Visual & 10.92 & 2.84 & 0.00 \\
\hline & & Sequential & -3.29 & 2.84 & 0.66 \\
\hline & & Sensitive & 7.74 & 2.84 & 0.04 \\
\hline & Visual & Visual & -10.92 & 2.84 & 0.00 \\
\hline & & Sequential & -14.21 & 2.88 & 0.00 \\
\hline & & Sensitive & 21.96 & 2.84 & 0.00 \\
\hline & Sequential & Visual & 3.29 & 2.84 & 0.66 \\
\hline & & Sequential & 14.21 & 2.88 & 0.00 \\
\hline
\end{tabular}

The results for the question and answer strategy are fairly straightforward. Table 3 shows the results of the Tukey's HSD comparisons of the means of reading comprehension scores of the different learning styles for the $Q \& A$ reading strategy. The active learners $(M=50.74, S D=9.78)$ did significantly better than the sensitive $(M=40.29, S D=11.07, p=.00)$, visual $(M=42.34, S D=9.42, p=.01)$ and sequential $(M=43.75, S D=9.59, p=.03)$ groups. This means that the question and answer strategy benefitted the active learners significantly more than the other learners.

Table 3: Tukey HSD Pairwise Comparison of RC Scores for Different Learning Styles Using the Q\&A Strategy

\begin{tabular}{|c|c|c|c|c|c|}
\hline $\begin{array}{l}\text { Dependent } \\
\text { Variable }\end{array}$ & $\begin{array}{l}\text { (I) Learning } \\
\text { Style }\end{array}$ & $\begin{array}{l}\text { (J) Learning } \\
\text { Style }\end{array}$ & $\begin{array}{l}\text { Mean } \\
\text { Difference (I-J) }\end{array}$ & Std. Error & Sig \\
\hline \multirow{12}{*}{$Q \& A$} & \multirow{3}{*}{ Active } & Sensitive & 10.4 & 2.42 & 0.00 \\
\hline & & Visual & 8.39 & 2.46 & 0.01 \\
\hline & & Sequential & 6.98 & 2.46 & 0.03 \\
\hline & \multirow{3}{*}{ Sensitive } & Sensitive & -10.4 & 2.42 & 0.00 \\
\hline & & Visual & -2.04 & 2.46 & 0.84 \\
\hline & & Sequential & -3.45 & 2.46 & 0.50 \\
\hline & \multirow{3}{*}{ Visual } & Sensitive & -8.39 & 2.46 & 0.01 \\
\hline & & Visual & 2.05 & 2.46 & 0.84 \\
\hline & & Sequential & -1.41 & 2.5 & 0.94 \\
\hline & \multirow{3}{*}{ Sequential } & Sensitive & -6.99 & 2.46 & 0.03 \\
\hline & & Visual & 3.46 & 2.46 & 0.50 \\
\hline & & Sequential & 1.41 & 2.50 & 0.94 \\
\hline
\end{tabular}


The SPANOVA addresses RQ 1, there were significant differences between learners using the keyword, rereading, Q\&A and no strategy conditions. However there was also an interaction effect indicating that these differences did not depend on the strategy conditions alone but were compound effects which depended on the learning styles as well. Based on the results of the no strategy condition of the first ANOVA, RQ 2 is answered in the negative. There are no significant differences between RC scores of learners having active, sensitive, visual and sequential learning styles in the absence of a reading strategy.

Answering RQ 3, there is a significant difference in RC scores of active learners when using different reading strategies. Active learners benefit most from the keyword and question and answer strategies but perform worse than usual when using the rereading strategy. With RQ 4, there is also a significant difference in RC scores of visual learners when using different reading strategies. Visual learners perform better with the keyword strategy but show no significant difference in RC scores when using the remaining three strategies. Moving on to RQ 5, sensitive learners also exhibit significant differences in RC scores when using different reading strategies. Unlike active learners, sensitive learners perform best with the rereading strategy but show no significant difference with the other three strategies. Answering RQ 6, sequential learners also display significant differences in $\mathrm{RC}$ scores when using different reading strategies. Similar to sensitive learners, sequential learners perform best with the rereading strategy but indicate no significant difference with the remaining three strategies.

\section{Discussion}

RQ 1 sought to ascertain if there was a significant difference between RC scores of learners using each of the different reading strategies used in this study. The results indicated that there was indeed a significant difference but this could not be accurately interpreted alone as there was also an interaction effect. What this meant was that the differences between the scores for each strategy were not based on the use of strategy alone but also depended on the learning style of the participants.

RQ 2 aimed to determine if there was a significant difference between RC scores of learners having different learning styles. It is interesting to note that for the no strategy condition there were no significant differences between the learning style groups. This means that the groups were similar in terms of their language and reading comprehension proficiency. Hence the active, sensitive, visual and sequential groups had approximately equal average scores on the RC tests taken in the no strategy condition. This makes it easier to draw inferences when dealing with the other reading strategy conditions because any difference will be directly attributable to the group since the RC levels were the same on the control condition. RQ 3, 4, 5 and 6 seek to understand how different learners respond to the different learning styles compared to their peers in other groups. The discussion will be presented according to how learners of each learning style responded to the treatment in the study. 


\section{Effect of Reading Strategies on Active Learners}

Active learners performed significantly better than the other learning style groups when using the keyword and Q\&A reading strategy. However these same learners performed significantly worse than any other group when using the rereading strategy. It should be pointed out that these results are interesting because reading is not the preferred mode of learning for active learners by definition. Active learners prefer to learn by doing and the very act of reading is a passive endeavour. One may argue that given their learning style preference active learners would perform badly on all reading comprehension tasks. However the results of this study indicate that active learners perform as well as other groups in the absence of integrated reading strategies and may perform better or worse than other groups in the presence of different reading strategies. The information processing theory offers some insight into this. According to Atkinson and Shiffrin (1969) information is processed in three stages -the sensory register, the working memory and the long-term memory. Knowledge acquisition starts at the sensory register stage when a person first responds to stimuli, which lasts .5 to 2 seconds (Hsieh, 2007). When reading with highlighted keywords, attention is drawn to the selected keywords and some degree of decision making takes place where students decide whether the information is important enough to fixate on (Schunk, 2004). Important information then enters the working memory stage where learners make meaningful connections between old and new information (Driscoll, 2005). In this stage schema is activated, which also borrows from the schema theory. Knowledge is retained in the long term memory as long as there is a purpose for it and it sufficient structure and significance; forgetting can easily happen if these conditions cease or are lost (Driscoll, 2005).

Active learners learn best when engaged in the learning material, through application and by trying things out (Felder \& Silverman, 1988). In a study carried out by Graf, Liu, Chen and Yang (2009), on 297 students testing the working memory for learners with different learning styles it was concluded that active and visual learners tended to have low working memory. This loosely translates to a low attention span or more specifically a low retention rate for items in the short-term memory both in terms of number of items and retention time. The use of the keyword strategy therefore not only brings the text to life but helps these learners focus on key points and filter out less important information which would have otherwise taken up precious short-term memory capacity. It also helps to trigger and activate schema which is a way to connect information and give it structure thus enabling it to be retained in the long term memory for a longer period of time. The activation of schema more importantly facilitates understanding as it gives learners a reference point to build ideas on and adds texture and nuance to information already acquired previously.

The success of active learners with the Q\&A strategy can also be explained by the information processing theory. The restructuring of the text into a question and answer format will invariably draw the reader's attention to both the question and the answer at the sensory register stage. Then in the working memory, this information becomes an associated chunk which is easier and faster to process (Hsieh, 2007). In this way, the information is more organized and structured information tends to remain accessible in the long term memory for a greater length of time. Active learners with the low working memory benefit from the faster processing and the simplification of information into 
chunks that can be associated easily with each other as well as with previously acquired schema. The question and answer format is also engaging in that it causes the reader to pause and encourages the reader to predict what happens next in the text which likely appeals to active learners.

The poor results obtained by active learners with the rereading strategy indicate an impediment to learning for students with an active propensity. The fact that reading is not the preferred mode of learning may have an important bearing on this phenomenon. Forcing an active learner to not only read a text once but reread it may cause boredom and overwork their low short-term memory capacity. As a result, they forget important facts and possibly even the point of the paragraph or passage. It becomes a case of not seeing the forest for the trees. Comparing the results for the rereading strategy with that of the no strategy condition, the active learners scored higher on the no strategy condition. Therefore it is safe to surmise that rereading has a deleterious effect on learning for active learners and proposing this strategy as a blanket solution for the classroom could put this group of learners at risk.

\section{Effect of the Reading Strategies on Sensitive Learners}

Sensitive learners performed well with the rereading strategy, significantly outperforming their active and visual counterparts but scoring slightly lower but not significantly less than the sequential learners. However sensitive learners scored the second lowest with the keyword strategy, significantly less than active and visual learners and was the lowest scoring group using the $Q \& A$ strategy. To understand this, one must bear in mind that sensitive learners prefer to learn in small increments and by focusing on facts and concrete learning material as opposed to theories. Compared to active and visual learners, sensitive learners have high working memory (Graf et al., 2009). As such, they have a high attention to detail and tend to assimilate much of what they read into their schema. One may imagine sensitive learners to be like librarians, indexing every piece of useful information and storing it in a complex archive of schemata to be retrieved when needed. Hence when accessing schema, it is important for sensitive learners to go through their process of making sense of the material for understanding to be achieved.

With the keyword strategy, there is a high likelihood the regular process is skipped since attention is drawn to individual words which may draw the reader away from the context the word is being used in. As mentioned by Schunk (2004), when coming across highlighted keywords, learners fixate on these words for a longer period of time. Given the rich schema a sensitive learner is used to dealing with, that individual word may be connected to various ideas which will result in miscomprehension of the passages intended meaning. The presence of keywords may serve as a distraction for sensitive learners instead of a point of focus to keep their attention on the subject matter. Giving an inordinate amount of attention to one word in a sentence may confuse or throw sensitive learners off their usual reading and thinking process.

With the rereading strategy, the text is first presented to the participants and when they click next to move on to the questions, certain portions of the text are replayed in a typewriter like animation. The next button is temporarily disabled thus not allowing the reader to skip the reread portions. From the information processing theory perspective, when a text is reread, the sensitive reader has an 
opportunity to re-evaluate input which was filtered by the sensory register. When reading a text the first time readers are often overwhelmed by the message or story and often do not have the metacognitive presence of mind to take a step back and assess which information is important and what they should be looking out for. When the text is read a second time around, the readers are already aware of the plot and what happens and can now focus on the minutiae and finer nuances of the text. Going through the text with a fine comb this way allows the reader to reiterate previous connections made between new and old information and strengthen structured schema already formed thus promoting information into the long term memory stage. According to a study conducted by Smith (2000), rereading is one of the most frequently used strategies by readers of all ages and itsproponents claim that activation of schema is an important contributor to how this strategy works. Hence, when sensitive learners use the rereading strategy, there is ample time for their associative process to take place and by connecting the context with their schema, a better understanding of the text is achieved. Unlike the keyword strategy, when specific phrases or sentences are repeated, the context in which the schema is being activated is still present allowing the sensitive learner to correctly index this new information with his or her currently existing archive. The complex process of sorting that the "librarian" has to go through is not compromised by lack of information as with the keyword strategy.

When sensitive learners use the Q\&A strategy, the restructuring of the text once again draws them away from their preferred process. With the Q\&A strategy the focus of portions of the text is drawn to the question posed before the paragraph. While this may serve to trigger schema and improve attention and understanding for certain learners, sensitive learners most likely perceive the $Q \& A$ strategy as a distraction and an obstacle to be overcome. It interferes with their indexing as once again a new parameter is being imposed on how they associate new information with existing schema. Given that sensitive learners prefer to focus on details and facts, this taking a step back and seeing the bigger picture is alien and uncomfortable for them. The constant paradigm shift happening throughout the passage may cause them to tire easily and lose interest and focus as they proceed through the text. Part of the way sensitive learners understand texts is by making causal relationships between pieces of information they are fed. Based on the results in appears that the presence of the Q\&A strategy impedes this process by distracting these learners and preventing important connections from being made.

\section{Effect of Reading Strategies on Visual Learners}

Visual learners performed best with the keyword reading strategy. With the keyword condition, visual learners scored significantly higher than the sensitive and sequential learners but scored slightly lower than active learners. Visual learners do significantly worse on the other hand with the rereading strategy compared to sensitive and sequential learners but perform significantly better than active learners. With the $Q \& A$ reading condition, visual as well as sensitive and sequential learners do significantly worse than active learners.

To understand this phenomena first an examination of the traits of a visual learner is warranted. Visual learners prefer to learn from diagrams, pictures or symbols over learning from lengthy texts or 
audio input. As the old adage so aptly puts it - a picture paints a thousand words. Hence visual learners prefer the simplicity and speed with which information can be transferred via graphical means over wordy explanations. Like active learners, visual learners have a low working memory which loosely translates into a low attention span (Graf et al., 2009). Reading is also not the preferred mode of learning for visual learners but given that reading is a task that cannot be avoided as part of the education system both active and visual learners have learnt to adapt.

When using the keyword reading strategy, visual learners will tend to skim the text moving from one keyword to another. The keywords serve as milestones, drawing the attention of the visual learner and keeping the focus of the passage clear while activating schema to facilitate understanding. Given the low working memory of visual learners, it is not uncommon for them to begin reading a text only to get lost somewhere in the middle and have to start again from the beginning. This is because they are focusing on their current place in the text that sometimes they forget the preceding sections and may have to start again to remember. Without the keywords, the text becomes a vast ocean of words with no buoys to navigate the deep and treacherous waters. How the keyword strategy is implemented is also crucial to the learning process. Keywords should be evenly distributed throughout the text and the choice of words is also important. Randomly chosen words that do not have congruence with the text can lead to confusion and cause readers to misunderstand the meaning and purpose of the passage. When done right, the keywords provide visual learners with a concise reference point so that they can continue reading the passage without having to refer to the beginning again. This provides much needed structure in the reading process and aids in achieving comprehension of the passage.

When using the rereading strategy, visual learners like their active counterparts are faced with exactly what they dread the most - lengthy texts. During the test the researcher observed a lot of tapping fingers, insistent clicking and impatient tapping of feet particularly with these two groups while they were doing the test with the embedded rereading strategy. It was clear that the reread portion of the text was often not only left unread but viewed as an intrusion and a cause for frustration for many of these learners. Research indicating that active and visual learners have low working memory had also suggested that these learners be given more autonomy over their own learning to mitigate the lack of attention span (Graf et al., 2009). The way the text played a second time somewhat robbed these learners of that autonomy and may have interfered with the already limited working memory by presenting an interruption, thus explaining the poorer results obtained by the active and visual learning style groups. The passiveness of the rereading strategy or at least the way it was implemented in this study clearly did not appeal to the visual and active learning style groups. Comparing the scores on the rereading strategy condition with the control condition the active and visual learners scored lower on the rereading condition whereas the sensitive and sequential groups scored higher on this measure than on the control condition.

With the $Q \& A$ condition, visual learners were once again faced with lengthy text material. Unlike the keyword strategy, the Q\&A strategy did not appear to have the effect of aiding attention span and helping the learner focus on the reading material at hand. This may be in part due to the absence of 
autonomy in the reading process. If this strategy were taught instead of embedded in the text, it may meet with greater success with this group of learners. In its present form, the Q\&A strategy is possibly seen as an obstacle to understanding and may confuse the learner. This is an especially potent danger when considering the low attention span of visual learners and how they may confuse the questions in the MCQ section with those in the passage.

Sequential learners performed the best among the learning style groups when using the rereading strategy. However these learners performed the worst when using the keyword strategy and were second best albeit significantly lower in terms of score for the Q\&A strategy.

To explain this, first an understanding of sequential learners must be acquired. Sequential learners learn in small incremental steps in a linear progression and seek logical stepwise paths in seeking solutions for problems (Felder \& Silverman, 1988). Like sensitive learners, sequential learners have in common a tendency for fastidiousness and a need for structure. These slow and steady learners tend to embrace the rereading strategy better than the other groups in the study. Sequential learners acquire knowledge by scaffolding their understanding with small building blocks of easily interpretable schema. It is important for sequential learners that they understand each step of a process before they can grasp the larger concept or theory. As such, the rereading strategy is best suited for these learners as each extra pass they make at the text allows for more small pieces of schema to fit into the larger jig-saw puzzle of their understanding of the subject matter. Each time a text is reread, the process of going over familiar ground grants sequential learners a deeper understanding of the text as they fit new information with existing schema and develop a more complex comprehension of the subject matter. As opposed to global learners who need to see the big picture first to understand how the smaller parts fit, sequential learners need to understand the minutiae of the theory or concept before they can grasp the entirety of it.

When using the keyword strategy, sequential learners face the same problem as sensitive learners. The keyword strategy provides a quick and easy method to digest the passage; however the sequential learner does not skim through texts well. As such, some important information may be missed leading to gaps in understanding. The keyword strategy also gives learners a look at the bigger picture or hints at what the paragraph or entire passage is about similar to how a movie trailer may hint at the plot of a movie. This may work for global learners but for sequential learners this may confuse them and draw their attention away from important details which they need to achieve proper comprehension. It is essential for sequential learners to read every sentence of a text so that nothing is missed which may result in impaired understanding.

It was predicted that sequential learners would struggle with the Q\&A strategy since this strategy seemed to be better suited for the opposite end of the dimension - the global learners. Although sequential learners did not do as well as the active learners they were the second highest scoring group. However their scores with the Q\&A strategy were only marginally higher than the scores on the control condition indicating there was little to no gain from using this strategy with this particular learning style. The Q\&A strategy may work for sequential learners because their very nature is to question each stage before understanding a subject. In the methodical dissection of an unfamiliar 
subject, sequential learners will question every logical step of the process seeking details to aid and scaffold their understanding. As such, the imposition of a question before a paragraph may seem normal to them. It does not however, add significantly to their learning process as this has very likely already been internalized as a general ground rule for all learning.

\section{Conclusions}

Many researchers have expounded the value of reading strategies in improving reading comprehension performance (Hellekjaer \& Hopfenback, 2012; Duke, Pearson, Strachan \& Billman, 2011; Grossman et al., 2010; Hattie, 2009; McNamara \& Magliano, 2009; Block \& Duffy, 2008; Block, Parris \& Whiteley, 2008 and Baker, Gersten \& Grossen, 2002). However few have attempted to tailor these strategies to fit specific learners. In this new age of learner centred teaching, it is imperative that the teaching methods used cater to every learner so that no one is left behind. The present study addresses itself to this problem by evaluating which reading strategy between the keyword, question and answer and rereading strategies do learners of active, sensitive, visual and sequential learning styles benefit the most from when performing reading comprehension tasks.

In summary, complex interactions exist between the learning styles and reading comprehension strategies tested in this study. Some strategies induced better performance for certain groups while lowering the performance of others. There is no blanket strategy that can be used to maximize the performance of all learning style groups without trading off the potential development of other groups. The keyword strategy consistently outperformed the control condition for all learning style groups and can therefore be safely implemented without adversely affecting the reading comprehension performance of any group. It should be noted however that better strategies exists that could benefit certain groups more. The researcher would also suggest that these results be interpreted with caution because the effect of learning styles on learning outcomes have been questioned in previous research as having a low correlation (Anderson, 2005 and Karns, 2006).

\section{Recommendations for Future Research}

At the beginning of this study, following the pilot test, half the learning style groups in the Felder Silverman Learning Styles Dimension were dropped due to insufficient sample sizes. The researcher reasoned that the results for the tested groups could be extrapolated to the groups that were removed. However having completed the research, it is hard to say if this remains true. The reading strategies that work for one group could also work for another group on the opposite end of the spectrum or may very well not work at all. To verify this future research should attempt to include all the learning style groups although this would mean canvassing an extremely large population to find the desired samples.

It should also be noted that the learners in the study have only one learning style preference but the vast majority of learners out there have two or more preferences on different scales of the dimension. For example an active learner may also be sensitive at the same time. Given that the reading strategies suited to sensitive group actually adversely affected the active group, it would be interesting to find out which strategy would suit a learner with two or more composite learning styles. 
INTERNATIONAL JOURNAL OF ACADEMIC RESEARCH IN BUSINESS AND SOCIAL SCIENCES Vol. 8, No. 12, Dec, 2018, E-ISSN: 2222-6990 @ 2018 HRMARS

This would not only make use of a larger percentage of the population but would also shed some light on the nature of the interaction between the learning style and reading strategy.

In the present study only the keyword, rereading and question and answer strategy are incorporated into the texts. There are hundreds of reading strategies available and future research should endeavour to find new and creative ways to implement these using multimedia and technology. Also the measured outcome in this study is reading comprehension but these strategies could be implemented in an audio context as well and outcomes measured could include listening skills, recall, vocabulary acquisition and writing among others. The efficacy of these strategies may differ depending on the task and it would be interesting to determine how and why differences exist.

Finally, learners in this study were categorized according to the Felder Silverman Learning Styles Dimension. There are a great many other learning styles models out there that could provide more insight into learner behaviour. Using several learning styles models to categorize learners in a repeated measures design may yield some new perspective on how learners process information. It would also be beneficial to add interviews or open ended questionnaire items to allow learners to express what they felt or thought as they were performing the exercises or tests. Information such as this would go a long way in aiding researchers understanding of the way different learners' process information.

\section{References}

Anderson, T. (2005). Distance learning-Social software's killer app? Australia: The Open \& Distance Learning Association of Australia

Atkinson, R. C. \& Shiffrin, R. M. (1969). Storage and Retrieval Processes in Long-Term Memory. Psychological Review. Vol 76(2), Mar 1969, 179-193.

Avila, E. \& Sadoski, M. (1996). Exploring new applications of the keyword method to acquire English vocabulary. Language learning, 46(3), 379-395.

Baker, S., Gersten, R. \& Grossen, B. (2002). Interventions for students with reading comprehension problems. Interventions for Academic and Behaviour Problems II: Preventive and Remedial Approaches.

Barrett, T. C. (1976). Taxonomy of reading comprehension. In Teaching reading in the middle class. eds. Smith R. And Barrett, T. C. Reading, M.A.: Addison-Wesley.

Benito, Y. M., Foley, C. L., Lewis, C. D. \& Prescott, P. (1993). The effect of instruction in questionanswer relationships and metacognition on social studies comprehension. Journal of Research in Reading, 16(1), 20-29.

Block, C. C. \& Duffy, G. G. (2008). Research on teaching comprehension: Where we've been and where we're going. Comprehension instruction: Research-based best practices, 2, 19-37.

Block, C. C., Parris, S. R. \& Whiteley, C. S. (2008). CPMs: A kinesthetic comprehension strategy. The reading teacher, 61(6), 460-470.

Businessballs Inc., (2007). Learning and Development resource for people and organizations, Chapman, A. Leicester, England. [Accessed on 6 November 2007]. Available: http://www.businessballs.com/kolblearningstyles.htm 
INTERNATIONAL JOURNAL OF ACADEMIC RESEARCH IN BUSINESS AND SOCIAL SCIENCES

Vol. 8, No. 12, Dec, 2018, E-ISSN: 2222-6990 @ 2018 HRMARS

Cohen, A. D. (1998). Strategies in learning and using a second language. London: Longman.

Cornis-Pope, M. \& Woodlief, A. (2003). The rereading/rewriting process: Theory and collaborative, on-line pedagogy. Intertexts: Reading pedagogy in college writing classrooms, 146-164.

DeCourcy, M. \& Birch, G. (1993). Reading and Writing Strategies Used in a Japanese Immersion Program.

Driscoll, M. P. (2005). Psychology of learning for instruction. Boston: Pearson

Duke, N., Pearson, D., Strachan, S. \& Billman, A. (2011). Essential elements of fostering and teaching reading comprehension. What research has to say about reading instruction, 51- 93.

Ellis, M. (1996). The Missing Link: Academic Study Skills - Between ESL and University Courses. In Jayakaran Mukundan \& Teh Chee Seng (eds.). Trends in English Language Teaching. (pp. 117121) Universiti Putra Malaysia Press, Serdang.

Ezell, H. K., Hunsicker, S. A., Quinque, M. M. \& Randolph, E. (1996). Maintenance and generalization of QAR reading comprehension strategies.Literacy Research and Instruction, 36(1), 64-81.

Ezell, H. K., Hunsicker, S. A. \& Quinque, M. M. (1997). Comparison of two strategies for teaching reading comprehension skills. Education and Treatment of Children, 365-382.

Fagan, B. (2003). Scaffolds to Help ELL Readers. Voices from the Middle, 11(1), 38-42.

Faust, M. A. \& Glenzer, N. (2000). "I could read those parts over and over": Eighth graders rereading to enhance enjoyment and learning with literature.Journal of Adolescent \& Adult Literacy, 234-239.

Fehrenbach, C. R. (1991). Gifted/Average Readers Do They Use The Same Reading Strategies?. Gifted Child Quarterly, 35(3), 125-127.

Felder, R. M. \& Silverman, L. K. (1988) “Learning and Teaching Styles in Engineering Education.” Engr. Education, Vol 78(7), 674-681.

Felder R. M. \& Soloman, B. A. Index of learning styles questionnaire. 2003. [Accessed December 24, 2008]. http:// www.engr.ncsu.edu/ learningstyles /ilsweb. html.

Finch, A. (2003). Reflective instruments for self-assessment in Korean EFL classrooms. Korea TESOL, 6(1), 63.

Graf, S., Liu, T. C., Chen, N. S. \& Yang, S. J. (2009). Learning styles and cognitive traits-Their relationship and its benefits in web-based educationalsystems. Computers in Human Behavior, 25(6), 1280-1289.

Green, M. (1998) Rapid retrieval of information: reading aloud with a purpose. Journal of Adolescent \& Adult Literacy 44(3), 234-239

Grossman, P., Loeb, S., Cohen, J., Hammerness, K., Wyckoff, J., Boyd, D. \& Lankford, H. (2010). Measure for measure: The relationship between measures of instructional practice in middle school English language arts and teachers' value-added scores (No. w16015). National Bureau of Economic Research.

Guillory, H. G. (1998). The effects of keyword captions to authentic French video on learner comprehension. Calico Journal, 15, 89-108.

Hattie, J. (2009). Visible learning: A synthesis of over 800 meta-analyses relating to achievement. London and New York: Routledge.

Hellekjær, G. O. \& Hopfenbeck, T. (2012). Lesing. Fokus på språk, 28, 84-124. 
INTERNATIONAL JOURNAL OF ACADEMIC RESEARCH IN BUSINESS AND SOCIAL SCIENCES

Vol. 8, No. 12, Dec, 2018, E-ISSN: 2222-6990 @ 2018 HRMARS

Louise, S.S. (2006). Children's reading comprehension and oral reading fluency in easy text. Reading and Writing, 19(2), 199-220.

Majid, F. A., Jelas, Z. M. \& Azman, N. (2006). Selected Malaysian adult learners academicreading strategies: A case study. Retrieved from http://www.face.stir.ac.uk/Majidp61.htm

McDaniel, M. A. \& Pressley, M. (1989). Keyword and context instruction of new vocabulary meanings: Effects on text comprehension and memory.Journal of Educational Psychology, 81(2), 204.

Mclntosh, M. E. \& Draper, R. J. (1995). Applying the question-answer relationship strategy in mathematics. Journal of Adolescent \& Adult Literacy, 39 (2), 120-131.

McNamara, D. S. \& Magliano, J. (2009). Toward a comprehensive model of comprehension. Psychology of learning and motivation, 51, 297-384.

Mesmer, H. A. E. \& Hutchins, E. J. (2002). Using QARs with charts and graphs. The Reading Teacher, 21-27.

Millis, K. K. \& King, A. (2001). Rereading strategically: The influences of comprehension ability and a prior reading on the memory for expository text. Reading Psychology, 22(1), 41-65.

Nathan, R. G. \& Stanovich, K. E. (1991). The causes and consequences of differences in reading fluency. Theory into practice, 30(3), 176-184.

Noor, N. M. (2006). Reading academic text: Awareness and experiences among university ESL learners. GEMA: Online Journal of Language Studies, 6(2), 65-78.

O'Donnell, P., Weber, K. P., Mclaughlin, T. F. (2003). Improving correct and error rate and reading comprehension using key words and previewing: A case report with a language minority student. Education and Treatment of Children, 26(3), 237-254.

Olmscheid, C. (1999). Reading Fluency: A Critical Component of Reading Instruction.

Ramaiah, M. (1997). Reciprocal teaching in enhancing the reading ability of ESL students at the tertiary level. Unpublished PhD Dissertation. University of Malaya, Kuala Lumpur

Ramaiah, M. \& Nambiar, M. K. (1993). Do undergraduates understand what they read: An investigation into the comprehension monitoring of ESL students through the use of textual anomalies. Journal of Educational Research, 15, 95-106.

Raphael, T. (1982). Question-answering strategies for children. The Reading Teacher, 36(2), 186-191.

Rekrut, M. D. (1996). Effective vocabulary instruction. The High School Journal, 66-74.

Sadoski, M. (2005). A dual coding view of vocabulary learning. Reading \& Writing Quarterly, 21(3), 221-238.

Schunk, D. H. (2004). Learning theories: An educational perspective, 4th Edition. Upper Saddle River, NJ: Prentice-Hall, Inc.

Shadish, W. R. Cook, T. D. \& Campbell, D. T. (2002). Experimental and Quasi-Experimental Designs for Generalized Causal Inference. Boston: Houghton-Mifflin.

Sharma, P. \& Hannafin, M. (2004). Scaffolding critical thinking in an online course: An exploratory study. Journal of Educational Computing Research, 31(2), 181-208.

Short, R. A., Kane, M. \& Peeling, T. (2000). Retooling the reading lesson: Matching the right tools to the job. The Reading Teacher, 284-295.

Shuler, C.A. (1999) Learning styles of criminal justice students: a study of two rural universities. Dissertation Abstracts International, 59 (8-A): 2854 
INTERNATIONAL JOURNAL OF ACADEMIC RESEARCH IN BUSINESS AND SOCIAL SCIENCES

Vol. 8, No. 12, Dec, 2018, E-ISSN: 2222-6990 @ 2018 HRMARS

Smith, M. C. (2000). The real-world reading practices of adults. Journal of Literacy Research, 32(1), 25-52.

Sorrell, A. L. (1996). Triadic Approach to Reading Comprehension Strategy Instruction. Paper presented at the $32 \mathrm{nd}$ Annual Conference of the Learning Disabilities 